\title{
The spatial patterns of taxonomic and phylogenetic diversity of seed plants with the climate factors across Ethiopia and Eritrea
}

\section{Biyansa H. Boru}

Wuhan Botanical Garden, CAS

Shengwei Wang

Wuhan Botanical Garden, CAS

Antony W. Njogu

Wuhan Botanical Garden, CAS

Anne C. Ochola

Wuhan Botanical Garden

Haiping Xin

Wuhan Botanical Garden, CAS

Yadong Zhou ( $\nabla$ zhouyd@wbgcas.cn )

Wuhan Botanical Garden, CAS https://orcid.org/0000-0001-6886-0662

Qingfeng Wang

Wuhan Botanical Garden, CAS

\section{Research article}

Keywords: Horn of Africa, Biodiversity, evolutionary, phylogenetic structures, environmental factors

Posted Date: November 20th, 2019

DOI: https://doi.org/10.21203/rs.2.9865/v2

License: (9) This work is licensed under a Creative Commons Attribution 4.0 International License.

Read Full License 


\section{Abstract}

Back ground: Biodiversity is the basic units and measures of the health of ecosystems that provide diverse goods and services for the well-being of human societies and other life forms. However, in this era due to the threats from climatic change and other human-driven environmental changes the earth's biodiversity is in a grave danger in the world wide. Here, we explored and mapped how the patterns of plant taxonomic diversity, phylogenetic diversity and structures vary across the geographical regions and with respect to environmental factors in Ethiopia and Eritrea in the horn of Africa by using different analyzing methods and diversity measuring indices for the same reasons.Results: Our analysis showed varied spatial distribution patterns of plant diversity across the region and with the gradients of climatic factors. While the central and southern highland parts of Ethiopia were found to be the primary centers of taxonomic diversity, the centers with higher phylogenetic diversity were found scattered in the region. The phylogenetic structures also vary greatly. About $70 \%$ of the floristic compositions in the region showed phylogenetically clustering patterns. Significant and different relationships were observed between the climatic variables and plant diversity and phylogenetic structures. Generally mean annual temperature were found to negatively and mean annual precipitation and elevational range have a positively impact the patterns of plant diversity in the region while variable patterns were observed among different plant growth forms. The phylogenetic structure patterns of woody and herbaceous plant groups in terms of NTI were found to be differently impacted by environmental factors.Conclusions: The patterns of plant diversity both from taxonomic and evolutionary perspectives vary greatly across the geographic and with climatic gradients in Ethiopia and Eritrea. Phylogenetic clustering patterns dominate the floristic compositions assembly in the region though considerable areas were found with floristics of phylogenetically overdispersing patterns. The patterns observed from evolutionary perspectives can provide more crucial information for conservation plans. It provide insights that enable the areas with high phylogenetic diversity and phylogenetically overdispersing assemblages to gain as much conservation attention as that of areas with high taxonomic diversity, given their species richness.

\section{Background}

Biodiversity is the basic unit and measure of the health of ecosystems. It plays an important roles in ecosystem functioning that provide supporting, provisioning, regulatory, and cultural services essential for the well-being of human society and other life forms $[1,2]$. However in recent decades due to the threats from climatic change and other human-driven environmental changes mainly habitat loss, fragmentations and degradations, in worldwide the earth's biodiversity is in a grave danger. To address such problems it needs a comprehensive study and clear understanding of the patterns of biodiversity in a given region. As a result a concern for biodiversity resources become a core topic for research and conservation programs $[3,4,5]$.

The patterns of plant biodiversity in different regions have long been well studied using traditional biodiversity assessment measures such as taxonomic diversity (TD) $[5,6]$. Nonetheless, the use of such measures alone may not provide complete pictures of diversity in a given region as these may fail to 
account for the evolutionary or lineage diversity of communities in a given region [5, 7]. A number of previous studies $[4,5,8,9]$ showed that the information of phylogenetic diversity is very crucial in identifying and preserving communities with greater traits and functions to maintain ecosystems with better potentials that could respond to different changes and be able to provide sustainable services. As a result of these facts, considering such evolutionary based criteria in biodiversity becomes an area of interest both for ecologists who are interested in understanding the underlying driving factors shaping the diversity patterns at multiple spatial scales and for the conservation biologists who need to prioritize conservation plans to preserve communities with such greater potentials. So for a better understanding of the patterns of plant diversity in a given region along with the underlying factors that shaped these patterns, the integration of the genetic and phylogenetic diversity measuring metrics with the taxonomic diversity measuring indices is paramount $[4,8]$.

Phylogenetic diversity (PD) or its derivatives such as standardized effect size phylogenetic diversity (SES_PD) which is defined as the sum of all the branch lengths connecting taxa in a defined region [10], is among such genetic and phylogenetic diversity measuring metrics used to quantify the phylogenetic composition (evolutionary relationships) of floristic assemblages in a given region similar to that of taxonomic diversity which measures the species composition of a given flora [11]. In addition to these phylogenetic diversity metrics, there are also phylogenetic structure measuring metrics like net relatedness index (NRI) and nearest taxon index (NTI) that are used to quantify the phylogenetic relatedness among coexisting species in regional plant assemblages and help to identify whether communities are composed of distinctly related species or closely related ones and then provide good insights for decision making in biodiversity conservation planning $[12,13]$. Although some studies $[4,5,9]$ showed a strong correlation between TD and PD, some others [eg. 8, 14] reported inconsistent relationships between them. As a result for decision making in conservation, both metrics are recommended to be estimated.

Numerous factors can be responsible for the variations in TD, PD and phylogenetic structures of floristic compositions assemblages across the space and along environmental gradients of a given region $[5,15]$. Biogeographically and evolutionary histories, habitat heterogeneities, edaphic heterogeneities, climatic variability and the influences of biotic factors such as interspecific interactions among the species in the community have been reported as some of these factors $[5,9,16,17]$. The associations among plant diversity and climatic factors have been observed by several researchers [e.g. 7, 9, 18] Temperature and precipitation are the two most commonly considered climatic variables in the studies concerned with understanding how climate factors shape the diversity and distribution patterns of plant community at the global scale $[19,20]$.The results of these studies have shown different relationships among the patterns of plant diversity, phylogenetic structure and the climatic variables. Their findings have also shown that these relationships vary between different plant life forms, i.e., herbaceous and woody plants have been found to be differentially influenced by climatic factors $[9,21]$. However, the findings about the influence of climatic and other environmental factors on the patterns of plant diversity and phylogenetic structures are inconsistent, especially among different life forms [e.g., 7, 9, 16, 18, 20, 22], this has also received little attention in our study area and thus calls for scientific investigation. 
Ethiopia and Eritrea are among the East African countries located in the horn of Africa, possessing the richest biodiversity in the continent that hosts 2 of the 35 world's biodiversity hot spots [6]. But the most threatened one due to the combined effects of destructive human activities and climatic changes [6, 2325]. Despite these facts, the studies that have been done in this region to understand the patterns of plant diversity along with the factors driving them were not comprehensive, mainly from the evolutionary perspective. The previous studies have only focused on TD aspects [26], while PD is more inclusive and imperative in conservation biology for the preservation of communities with greater phylogenetic diversity that maximize the potential of the local flora to respond to future changes and provide sustainable services $[4,9,16]$. Therefore, there are gaps in this region in understanding the patterns of plant diversity from the evolutionary perspectives and in considering this dimension in conservation plans.

Thus, in this study, our aim was to investigate how the patterns of plant TD, PD and phylogenetic structures vary across the geographical regions and with respect to variations in climatic factors in Ethiopia and Eritrea, in the horn of Africa mainly so as to gain insights of phylogenetic diversity into the flora of the region. Specifically, we aimed to answer the following questions: (1) how spatial patterns of seed plants' phylogenetic diversity vary across Ethiopia and Eritrea and related with the patterns of their taxonomic diversity? (2) How the floristic compositions phylogenetic structures assembled across the region? (3) How environmential factors influenced the patterns of plants' taxonomic diversity, phylogenetic diversity and community phylogenetic structures in the region and how these influences of environmential factors vary between woody and herbaceous plant groups?

\section{Materials And Methods}

\section{Study area and climate data}

The study was conducted in Ethiopia and Eritrea, which are located in the Horn of Africa between $3^{\circ}$ to $18^{\circ} \mathrm{N}$ and $33^{\circ}$ to $48^{\circ} \mathrm{E}$, covering a total area of ca. 1.251 million $\mathrm{km}^{2}$, and characterized with a wide variety of landscapes, diverse geological formations and topographic features with marked contrasts in relief where the altitude ranges from about $125 \mathrm{~m}$ below sea level to $4,620 \mathrm{~m}$ above sea level [Fig. 1;26, $27,28]$.Due to these diverse topographic features and wide elevational ranges the region is also known to have very variable macro and micro-climatic conditions and experience large spatial variations in temperature and precipitations $[25,29]$. The mean annual precipitations across the region vary from 500 $\mathrm{mm}$ to $2200 \mathrm{~mm}$ while the mean annual temperature ranges from below $10^{\circ} \mathrm{C}$ to $30^{\circ} \mathrm{C}$ with very high local variability. The transition between lowlands and highlands is commonly very sharp, resulting in a variety of climates that vary from very arid to very humid typical of equatorial mountains. Moreover, precipitation varies with latitude, generally decreasing from south to north. As the result of these physiographic and climatic features the region is endowed with a complex mosaic of habitats and ecological zones ranging from desert scrubland vegetation to alpine vegetations in high mountain areas that are inhabited with rich diversity of plants, animals and microbial life forms [28]. To analyze the spatial patterns of plant diversity in this region in terms of the proposed parameters, we used uniform grid cells of $0.5^{\circ}$ latitudes $\times 0.5^{\circ}$ longitudes as units of analyses (Fig. 1). 


\section{Climatic data}

In order to examine the relationships between the climatic factors and the diversity and structures of plant communities across the geographical regions of Ethiopia and Eritrea, we considered the mean annual temperature and precipitation as important ecological drivers of plant taxa distributions. The mean annual temperature and precipitation data as climate variables for each of the grid cells were extracted from global climate model Worldclim [30, available: http://www.worldclim.org/] using ArcGIS 10.5 [31].

\section{Data sources}

The plant data sets used in this study were extracted from the published Flora volumes of Ethiopia and Eritrea (FEE) [32] and from the global biodiversity information facility (GBIF, https://www. gbif.org/). Based on our sources, we compiled a comprehensive checklist of seed plants belonging to Ethiopia and Eritrea. The database consisted of species names, family names, life forms, altitudinal and geographical distribution information's of each of the species. Then, to ensure a standard taxonomy in the analyses we adjusted the family and genera of these plants as per the Plant List version 1.1 (available at http://www.theplantlist.org), using the R package "plantlist" [33], where the circumscription of the angiosperm family is generally consistent with APG III [34]

\section{Taxonomic metrics}

We extracted the minimum and maximum elevations of each of these grids using ArcGIS, and then the plant data records in each of these cells were obtained based on the altitudinal and geographical distribution range information of each plant as described in the sources (FEE). To assess the spatial taxonomic diversity patterns of seed plant distributions for total, woody and herbaceous plant groups across the geographic regions of these countries we calculated and mapped the genus richness of these plants at the $0.5^{\circ}$ grid cell levels. The uniform size grid cells were used to eliminate the effect of the differences in area of the spatial units of analysis [35].

\section{Phylogeny construction}

We constructed a phylogenetic tree for all the seed plants we compiled for analysis and also for the woody and herbaceous plant groups separately at species level using the R function 'V.PhyloMaker' provided by Qian and Jin (2019) [36]. For the absent species, we used the Scenario S3 approach of the function 'V.PhyloMaker' to add them to their families or genera in the supertree using the same approach as used in Phylomatic and BLADJ [37, 38].

\section{Phylogenetic metrics}

To examine the variation in phylogenetic diversity of floristic compositions across the space and with respect to climatic factors in Ethiopia and Eritrea, we quantified the standardized effect size phylogenetic diversity (SES_PD) as standardized PD metrics because PD is strongly and positively correlated with TD 
[4]. For this PD was standardized to the observed taxa richness by using the null model randomization method by shuffling the taxa labels across the phylogeny 999 times. Then SES_PD was computed as equation below $[5,38]$

$\mathrm{SES} \_\mathrm{PD}=\left(\mathrm{PD}_{\text {observed }}-\right.$ mean $\left.\mathrm{PD}_{\text {randomized }}\right) / \mathrm{sdPD}_{\text {randomized }}$

$\mathrm{PD}_{\text {observed }}$ is the metric value of the communities under the study; the $\mathrm{PD}_{\text {randomized }}$ is the mean metric value of the null communities and SdPD randomized is the standard deviation for the metric value of the null communities.

To examine the phylogenetic structures of floristic diversity assemblages that quantify the degree of phylogenetic relatedness among floristic compositions in each unit, we calculated the net relatedness index (NRI) and the nearest taxon index (NTI) using the following models [12]:

$$
\begin{aligned}
& \mathrm{NRI}=-1 \times\left(\mathrm{MPD}_{\text {observed }}-\mathrm{MPD}_{\text {randomized }}\right) / \mathrm{sdMPD}_{\text {randomized }} \\
& \mathrm{NTI}=-1 \times\left(\mathrm{MNTD}_{\text {observed }}-\mathrm{MNTD}_{\text {randomized }}\right) / \mathrm{sdMNTD}_{\text {randomized }}
\end{aligned}
$$

Where, MPD is a diversity metrics measuring mean phylogenetic distance among all pair of taxa in the assemblage, MPD observed is the MPD metric values of the community under the study, MPDrandomized is the mean value of MPD for the null communities, and sdMPD randomized is the standard deviation of the phylogenetic distances in the null communities [12]. MNTD represents the mean phylogenetic relatedness between each taxon and its nearest relative in the assemblage. MNTD observed is the MNTD metric values of the community under the study, MNTD randomized is the metric value for the null communities, and sdMNTD randomized is the standard deviation of phylogenetic distances in the null communities [39]. To maintain the statistical significance of the observed patterns, the randomization process for each of the null communities were repeated 999 times. Positive values of NRI and NTI indicate phylogenetically clustering communities while their negative values reveal phylogenetically overdispersing communities.

The analysis of PD and phylogenetic structures were performed in R software, using 'picante' package [40]. The spatial patterns of diversity and phylogenetic structure were analyzed and mapped with ArcGIS 10.5 [31]. To assess the relationships among plant diversity indices, phylogenetic structure attributes and climatic factors, we performed simple linear regression analysis and fitted the model for each plant group in $\mathrm{R}$ software [41].

\section{Results}

\section{Seed plants data composition}


The total plant data compiled from the whole study areas (485 grid cells) and used for this analysis was composed of 1401 genera belonging to 172 families of seed plants. From these, 380 genera belonging to 101 families were woody seed plants while the remaining 1021 genera from 139 families were herbaceous seed plants. In this data set, Fabaceae, Poaceae, Asteraceae, cypraceae, Malvaceae, Acantaceae and Lamiaceae were the top rich families each represented by more than 200 species per family while Euphorbia, Cyperus, Crotalaria, Indigofera, Commiphora, Ipomoea and Habenaria were the most specise genera in the data set containing more than 50 species per genus.

\section{Spatial patterns of plant diversity and phylogenetic structures}

Very variable spatial distribution patterns of taxonomic and phylogenetic diversity of seed plants were observed across the geographic regions of Ethiopia and Eritrea. The species richness were found to range from 52 to 2387 for the total, 12 to 948 for woody and 40 to 1954 for herbaceous plant groups per grid cells (Fig. 2a囚c). The highest species richness of the total, woody and herbaceous plant groups were all found in montane areas of the central and southern parts of Ethiopia and the lowest were all found in lowland areas of Ethiopia and Eritrea (Fig. 1; Fig. 2a-c). The phylogenetic diversity patterns of these plants in terms of SES_PD were found to range from -7.471 to 2.996 for total, -4.161 to 3.635 for woody and -6.499 to 1.162 for herbaceous plants (Fig. 2d-f). The area of high SES_PD is mainly found in western Ethiopia, and also in the Bale mountains area and northern Ethiopia (Fig. $2 d-f$ )..

The phylogenetic structures (NRI and NTI) of the floristic composition were also found to be varied across the region (Fig. $2 \mathrm{~g}-\mathrm{I}$ ). The majorities of the grid cells across the region showed phylogenetic clustering (positive values of NRI and NTI) implying that the co-occurring species of the floristic diverstity in most areas of the region are more closely related than those that are expected from null model regions. Still floristic diversity in considerable areas of the region have also shown phylogenetic overdispersion patterns (negative values of NRI and NTI) with some variations among different floristic compositions in which relatively higher of woody plant groups showed overdispersion patterns.

\section{Patterns of plant diversity and phylogenetic structures with respect to environmental factors}

The result of linear and nonlinear regression model showed various association patterns among environmental variables and plant diversity and phylogenetic structures. According to the result of this analysis highly significant and negative relationships were found between the mean annual temperature and the species richness (Fig. 3a) and SES_PD (Fig. 3d) of total species, while mean annual precipitation and elevational ranges with species richness (Fig. 3b,c) and SES_PD (Fig. 3e,f) of these plant groups were found to be significantly and positively related.

The relationships between the mean annual temperature and the species richenss (Fig. 4,5 a) and SES_PD (Fig. 4,5 d) of woody and herb plant groups were also found to be highly significant and negative while these relationships were significant positive between the mean annual precipitation and elevational ranges with species richness (Fig.4,5 b,e) and SES_PD (Fig. 4,5 c,f) of these plant groups. 
The result of the simple linear and nonlinear regression model analysis also indicated that the gradients of mean annual temperature and precipitations have differently influenced the phylogenetic structures of these plant communities across the geographical regions of Ethiopia and Eritrea. The model identified the total species was highly consistent with woody and herbaceous plants on NRI, with a significant positive correlation at mean annual temperature (Fig. 3,4,5 g) and a significant negative correlation between mean annual precipitation and altitude range (Fig. 3,4,5 h,i). NTI of all species was positively correlated with mean annual temperature and negatively correlated with mean annual precipitation and altitude range (Fig. $3 \mathrm{j}, \mathrm{k}, \mathrm{l}$ ). However, it is worth noting here that the herb exhibits a completely different relationship with all species. The NTI of the herb is negatively correlated with mean annual temperature and positively correlated with mean annual precipitation and altitude range (Fig. 4 j,k,l). There was no significant correlation between NTI and mean annual temperature in woody plants, but negatively correlated with mean annual precipitation and altitude range (Fig. 5 j,k,l).

\section{Discussion}

In this study, we analyzed the patterns of taxonomic and phylogenetic diversity as well as the phylogenetic structures of seed plants as a whole and for woody and herbaceous plant groups separately across the geographical regions of Ethiopia and Eritrea. We also examined how these patterns vary with respect to variation in environmental factors. All indices of diversity and phylogenetic structures of these floristics were found to be variable from region to region. Areas of high species richness were found from the central and southern parts of the region. This could be because of the existence of complex topographic features and relatively high precipitations in these parts of the region. Moreover, this could also be associated with the relatively high intensity of plant collection and scientific investigation made in these parts of the region than other parts [27, 42]. We used standardized effect size phylogenetic diversity (SES_PD) to examine the spatial variations in phylogenetic diversity of seed plants across this region because this metric reflects the actual variations by controlling the effect of variations in species richness among floristic compositions [5, 8]. While this metric was used, we found the areas of high phylogenetic diversity apart from the areas of high taxonomic diversity distributed in different parts of the region. Across the region the highest level of PD was found in the western, southwestern, north central highlands of Ethiopia and from central highlands of Eritrea with some variations for different growth forms (Fig. 2d-f). This indicates the importance of considering the phylogenetic diversity perspectives of floristic compositions in biodiversity assessment to specify the potential areas for conservation planning in a given region given their species richness $[4,5,8]$. In the Ethiopia and Eritrea region, we strongly recommend strengthening species and habitat surveys in western, northern and central Ethiopia. Develop a more comprehensive protection strategy from the perspective of diversity and evolution.

The phylogenetic structure of the flora of Ethiopia and Eritrea showed strong variations across the region. The majority (in average $>70 \%$ ) of grid cells in the region showed phylogenetic clustering patterns (positive values of NRI and NTI) while only cells in $<30 \%$ of the areas were found to have phylogenetic overdispersion patterns (negative values of NRI and NTI). These patterns were found to be different for different plant groups. Relatively more grid cells of woody plant groups showed phylogenetic over 
dispersion (negative values of NRI and NTI) than others. For woody plants out of the 485 grid cells across the region about 185 (38\%) of them had negative values of NRI and $15 \%$ of them had negative values of NTI while only $17.5 \%$ and $2 \%$ of the grid cells had negative values of NRI and NTI respectively for herbaceous assemblages. Our results also found that changes in altitude range are related to the dispersion and aggregation of phylogenetic structural patterns. This is because altitude changes can reflect the complexity of the species habitat and the heterogeneity of the environment, thus affecting the observed patterns. The complex ecosystems, topographic features and climatic changes resulting from the past complex geological events $[27,43]$ may have shaped the various phylogenetic structures across the region by facilitating the species assemblages in the floristics.

Concerning the association between environmential variables and plant diversity patterns, our results revealed that both taxonomic diversity and phylogenetic diversity had the same tendency in which they showed significant and positive relationships with the mean annual precipitation and significant and negative relations with the mean annual temperature and elevational range regardless of the plant life forms. These were in accordance with other findings from other regions [18, 20,44,45]. The influences of environmential variables on the phylogenetic structure in terms of NRI showed similar trends for all plant groups, while in terms of $\mathrm{NTI}$, the influence of environmential variables showed different patterns on phylogenetic structures of total, herbaceous and woody plant groups. The NTI of herbaceous assemblages showed significant decreased tendency patten with the mean annual temperature (Fig. 4j) and significant incresed tendency patterns with the mean annual precipitation and elevation (Fig. 4kl), these patterns were found to be the opposite for woody and total assemblages (Fig. 3 \& 4).

Previous studies have reported that generally the diversity and structures of plants assemblages in a given region are regulated by the combined effects of ecological interactions, environmental filtering and evolutionary processes $[9,45]$. In general, woody plants may have climate-dominated niches, whereas herbaceous plants may have edaphic and microhabitat-dominated niches, and the climate filtering process presumably has played a greater role in structuring species into local communities for woody plants than for herbaceous plants (Zhou et a., 2018; Qian et al., 2017; Ricklefs \& Latham, 1992).

Therefore, on the macro scale, the unfavorable environment can lead to the better survival of the woody plants with closer interspecific relationship in the community, for it is believed that closely related species share similar ecological traits and strategies to adapt to harsh environments. For instense, there are a large number of Acacia plants adapted to the arid environment in the northwest of Ethiopia (?????). Herbaceous plants can always adapt to new climatic conditions several times faster than woody plants for the latter have longer reproductive cycles and tend to accumulate genetic changes at slower rates (Smith \& Beaulieu, 2009), therefore, compared with woody plants, herbaceous ones have significantly higher diversity and more random phylogenetic structure (NTI) in the lowland of Ethiopia with higher temperature and lower precipitation (Giorgis et al., 2016; Molina Montenegro \& Naya, 2012; Yang et al., 2018).

\section{Conclusions}


In conclusion, the results of our study found that the patterns of plant diversity, both in the taxonomic and phylogenetic perspective vary greatly across the geographic regions of Ethiopia and Eritrea. While the central and southern parts of the region were found to be the center of taxonomic diversity, centers of high phylogenetic diversity were found scattered in the region. Phylogenetic clustering patterns dominate the plant community assembly in the region though considerable areas were found with phylogenetically overdispersed communities. Significant and different relationships between the plant diversity and climate factors were observed. The mean annual temperature and precipitation negatively and positively influenced the diversity of plant communities in the region respectively. While the mean annual temperature and precipitation, respectively negatively and positively influenced the phylogenetic structures of all the plant groups in terms of NRI, these patterns were different among different life forms in terms of NTI. In addition to climatic factors, we also support that the other deterministic processes, mainly environmental filtering process played major roles in shaping the observed diversity and phylogenetic structure patterns in this region. Considering plant PD and phylogenetic structure in biodiversity conservation prioritizations and focusing on areas of communities with high species richness and overdispersed structures in conservation have been reported as an efficient criterion to preserve communities with greatest features and functions $[4,8]$. So, in our study region, since variable diversity and phylogenetic structure patterns were found across the region, we suggest that conservation actions should focus on all parts and the areas with high phylogenetic diversity and phylogenetically overdispersed community assemblages should gain as much conservation actions as areas of high TD for the maintenance of ecosystems with future diversification options and better potentials to respond to future global changes and ensure the continuous provision of associated services.

\section{Abbreviations}

TD: Taxonomic diversity

PD: Phylogenetic diversity

SES_PD: Standardized effect size phylogenetic diversity

NRI: Net relatedness index

NTI: Nearest taxon index

FEE: Flora of Ethiopia and Eritrea

\section{Declarations}

\section{Ethics approval and consent to participate}

Not applicable.

\section{Consent to publish}


Not applicable.

\section{Availability of data and materials}

The datasets used and analyzed in this study are available from the corresponding author on reasonable request.

\section{Competing interests}

The authors declare that they have no competing interests.

\section{Funding}

This study was supported by the fund of Sino-Africa Joint Research Center, CAS, China (Y323771W07 and SAJC201322) and the National Natural Science Foundation of China (31800176).

\section{Authors' contributions}

BHB and SW compiled the datasets used in the study. BHB and SW developed the study methods with valuable contributions from YZ. SW analyzed the data. BHB and SWwrote the manuscript with contributions and modifications from YZ. WQ and XH coordinate and led the work and commented on the manuscript. ACO edited the English grammar. All the Authors contributed in reading, editing, commenting and approving the final manuscript.

\section{Acknowledgments}

We are very grateful to the botanists who compiled the Flora of Ethiopia and Eritrea.

\section{References}

1. Hooper DU, Chapin FS, Ewel JJ, Hector A, Inchausti P, Lavorel S et al. Effects of biodiversity on ecosystem functioning: a consensus of current knowledge. Ecol Monogr. 2005; 75: 3-35. https://doi.org/10.1890/04-0922

2. Millennium Ecosystem Assessment. Ecosystems and human well-being: biodiversity synthesis. Washington, World Resources Institute. 2005.

3. HUANG J, CHEN J, YING J, MA K. Features and distribution patterns of Chinese endemic seed plant species. J Sys Evolu. 2011; 49: 81-94. doi:1111/j.1759-6831.2011.00119.x

4. Li R, Kraft NJ, Yu H, Li H. Seed plant phylogenetic diversity and species richness in conservation planning with in a global biodiversity hotspot in eastern Asia. Conserv Biol. 2015; 29: 1552-62. https://doi.org/10.1111/cobi.12586

5. Wang, S., Boru, B. H., Njogu, A. W., Ochola, A. C., Hu, G., Zhou, Y., \& Wang, Q. Floristic composition and endemism pattern of vascular plants in Ethiopia and Eritrea. Journal of Systematics and Evolution. 2019. https://doi.org/10.1111/jse.12527 
6. Mittermeier RA, Turner WR, Larsen FW, Brooks TM, Gascon C. Global biodiversity conservation: the critical role of hotspots. In: Zachos FE, Habel JC (Eds.) Biodiversity hotspots: distribution and protection of priority conservation areas. Springer-Verlag, Berlin. 2011; pp 3-22

7. Thornhill AH, Baldwin BG, Freyman WA, Nosratinia S, Kling MM, MoruetaHolme N, et al. Spatial phylogenetics of the native California flora. BMC Biol. 2017; 15: 96. https://doi.org/10.1186/s12915017-0435-x

8. Forest F, Grenyer R, Rouget M, Davies T J, Cowling R M, Faith D P, et al. Preserving the evolutionary potential of floras in biodiversity hotspots. Nature. 2007; 445: 757-60. https://doi.org/10.1038/nature05587

9. Yan YJ, Yang X, Tang ZY. Patterns of species diversity and phylogenetic structure of vascular plants on the Qinghai-Tibetan Plateau. Ecol Evol. 2013; 3: 4584-95. https://doi.org/10.1002/ece3.847

10. Faith DP. Conservation evaluation and phylogenetic diversity. Biol Conser. 1992; 61: 1-10. https://doi.org/10.1016/0006-3207(92)91201-3

11. Lu LM, Mao LF, Yang T, Ye JF, Liu B, Li HL, et al. Evolutionary history of the angiosperm flora of China. Nature. 2018; 554: 234-38. https://doi.org/10.1038/nature25485

12. Webb CO. Exploring the phylogenetic structure of ecological communities: an example for rain forest trees. Am Nat. 2000; 156: 145-55. https://doi.org/10.1086/303378

13. Kembel SW, Hubbell SP. The phylogenetic structure of a neotropical forest tree community. Ecology. 2006; 87: 86-99. https://doi.org/10.1890/0012-9658(2006)87[86:TPSOAN]2.0.C0;2

14. Tucker CM, Cadotte MW, Davies TJ, Rebelo AG. Incorporating geographical and evolutionary rarity into conservation prioritization. Conser Biol. 2012; 26: 593-601. https://doi.org/10.1111/j.15231739.2012.01845.x

15. Baldwin BG, Thornhill AH, Freyman WA, Ackerly DD, Kling MM, MoruetaHolme N, et al. Species richness and endemism in the native flora of California. Am J Bot. 2017; 104: 1-15. https://doi.org/10.3732/ajb.1600326

16. Moro MF, Silva IA, de Araújo FS, Nic Lughadha E, Meagher TR, Martins FR. The role of edaphic environment and climate in structuring phylogenetic pattern in seasonally dry tropical plant communities. PLoS One. 2015; 10(3): e0119166. https://doi.org/10.1371/journal.pone.0119166

17. Gastauer M, Saporetti-Junior AW, Valladares F Meira-Neto JAA. Phylogenetic structures reveal differences in plant community assembly of an oligotrophic white-sand ecosystem from the Brazilian Atlantic forest. Acta Bot Bras. 2017; 31(4): 531-38. https://doi.org/10.1590/0102$33062016 a b b 0442$

18. Kreft H, Jetz W. Global patterns and determinants of vascular plant diversity. Proc Natl Acad Sci USA. 2007; 104: 5925-30. https://doi.org/10.1073/pnas.0608361104

19. Moles AT, Perkins SE, Laffan SW, Flores-moreno H, Tindall M L, Sack L, et al. Which is a better predictor of plant traits: temperature or precipitation? J Veg Sci. 2014; 25(5): 1167-80. https://doi.org/10.1111/jvs.12190 
20. Qian H, Hao Z, Zhan J. Phylogenetic structure and phylogenetic diversity of angiosperm assemblages in forests along an elevational gradient in Changbaishan, China. J Plant Ecol. 2014; 7(2): 154-65. https://doi.org/10.1093/jpe/rtt072

21. Díaz S, Kattge J, Cornelissen JH, Wright IJ, Lavorel S, Dray S, et al. The global spectrum of plant form and function. Nature. 2016; 529: 167-71. https://doi.org/10.1038/nature16489

22. Scherson RA, Thornhill AH, Urbina-Casanova R, Freyman WA, Pliscoff PA \& Mishler BD. Spatial phylogenetics of the vascular flora of Chile. Mol Phylogenet Evol. 2017; 112: 88-95. https://doi.org/10.1016/j.ympev.2017.04.021

23. Vivero JL, Kelbessa E, Demissew S. Progress on the red list of plants of Ethiopia and Eritrea: conservation and biogeography of endemic flowering taxa. In: Ghzanfar SA, Beentje HJ (Eds.). Taxonomy and ecology of African plants, their conservation and sustainable use. Royal Botanic Gardens, Kew. 2006; pp 761-78

24. Husen A, Mishra VK, Semwal K, Kumar D. Biodiversity status in Ethiopia and Challenges. In: Bharati KP, Chauhan A, Kumar P (Eds.) Environmental Pollution and Biodiversity. Discovery Publishing House Pvt Ltd, New Delhi. 2012; pp 31-79

25. Gebretsadik, T. Causes for biodiversity loss in Ethiopia: a review from conservation perspective. Journal of Natural Sciences. 2016; 6(11): 32-40

26. Friis I, Thulin M, Adsersen H Buerger A-M. Patterns of plant diversity and endemism in the horn of Africa. Biologiske Skrifter. 2005; 55: 289-314

27. Ethiopian Mapping Authority. The national atlas of Ethiopia. EMA, Addis Ababa. 2019

28. Friis I, Demissew S, Breugel PV. Atlas of the potential vegetation of Ethiopia. The Royal Danish Academy of Sciences and Letters, Copenhagen. 2010

29. Fazzini M, Bisci C, Billi P. The climate of Ethiopia. In: Bliip P (Ed.) Landscapes and land forms of Ethiopia. Springer, Dordrecht. 2015; pp 65-87.

30. Hijmans RJ, Cameron SE, Parra JL. Very high resolution interpolated climate surfaces for global land areas. Int J Climatol. 2005; 25: 1965-78. https://doi.org/10.1002/joc.1276

31. AricGIS release 10.5. Readlands, California. 2016

32. FEE editors. Flora of Ethiopia and Eritrea. National Herbarium, AAU, Ethiopia. 1995-2012

33. Zhang JL. Plantlist: looking up families of higher plants. Available at: http://R-Forge.Rproject.org/projects/plantlist/. 2015

34. Angiosperm Phylogeny Group. An update of the angiosperm phylogeny group classification for the orders and families of flowering plants: Apg III. Bot J Linn Soc. 2009; 161: 105-21. https://doi.org/10.1111/j.1095-8339.2009.00996.x

35. Zhang DC, Ye JX, Sun H. Quantitative approaches to identify floristic units and centres of species endemism in the Qinghai-Tibetan Plateau, southwestern China. J Biogeogr. 2016; 43: 2465-76. https://doi.org/10.1111/jbi.12819 
36. Jin Y, Qian H. V. PhyloMaker: an R package that can generate very large phylogenies for vascular plants. Ecography. 2019; 42: 1353-1359. https://doi.org/10.1111/ecog.04434

37. Wikström N, Savolainen V, Chase MW. Evolution of the angiosperms: calibrating the family tree. $P$ Roy Soc B-Biol Sci. 2001; 268: 2211-20. https://doi.org/10.1098/rspb.2001.1782

38. Webb, C.O., Ackerly, D.D., Kembel, S.W. Phylocom: software for the analysis of community phylogenetic structures and trait evolution. Bioinformatics. 2008; 24, 2098-100. https://doi.org/10.1093/bioinformatics/btn358

39. Webb CO, Ackerly DD, McPeek MA. Phylogenies and community ecology. Annu Rev Ecol Syst. 2002; 33: 475-505. https://doi.org/10.1146/annurev.ecolsys.33.010802.150448

40. Kembel SW, Cowan PD, Helmus MR, Cornwell WK, Morlon H, Ackerly DD, et al. Picante: R tools for integrating phylogenies and ecology. Bioinformatics. 2010; 26: 1463-64. https://doi.org/10.1093/bioinformatics/btq166

41. R Core Team. R: a language and environment for statistical computing. $R$ foundation for statistical computing, Vienna. 2017

42. Demissew S, Nordal I, Herrmann C. Diversity and endemism of the western Ethiopian escarpment a preliminary comparison with other areas of the Horn of Africa. Biologiske Skrifter. 2005; 55: 315-30

43. Friis I, Edwards S, Kelbessa E. Diversity and endemism in the flora of Ethiopia and Eritrea. what do the published flora volumes tell us? Biologiske Skrifter. 2001; 54: 173-93

44. Chun JH, Lee CB. Diversity patterns and phylogenetic structure of vascular plants along elevational gradients in a mountain ecosystem, south Korea. J Mt Sci. 2018; 15(2): 280-95. https://doi.org/10.1007/s11629-017-4477-x

45. Wang Z, Fang J, Tang Z. Relative role of contemporary environment versus history in shaping diversity patterns of China's woody plants. Ecography. 2012; 34: 1-10. https://doi.org/10.1111/j.1600-0587.2011.06781.x.

46. Ricklefs RE. History and diversity: explorations at the intersection of ecology and evolution. Am Nat. 2007; 170: 56-70. https://doi.org/10.1086/519402

47. Zhou Y, Chen S, Hu G, Mwachala G, Yan X, Wang. Species richness and phylogenetic diversity of seed plants across vegetation zones of Mount Kenya, East Africa. Ecol Evol. 2018; 8: 893039. https://doi.org/10.1002/ece3.4428

48. Lee $\mathrm{CB}$, Chun JH. Environmental drivers of patterns of plant diversity along a wide environmental gradient in Korean temperate forests. Forests. 2016; 7(1): 19. https://doi.org/10.3390/f7010019

49. Blaser WJ, Sitters J, Hart SP. Facilitative or competitive effects of woody plants on understorey vegetation depend on $\mathrm{N}$-fixation, canopy shape and rainfall. J Ecol. 2013; 101: 1598-1603. https://doi.org/10.1111/1365-2745.12142

50. Belay TA, Moe SR. Assessing the effects of woody plant traits on understory herbaceous cover in a semiarid rangeland. Environ Manage. 2015; 56(1): 165-75. https://doi.org/10.1007/s00267-0150491-3 


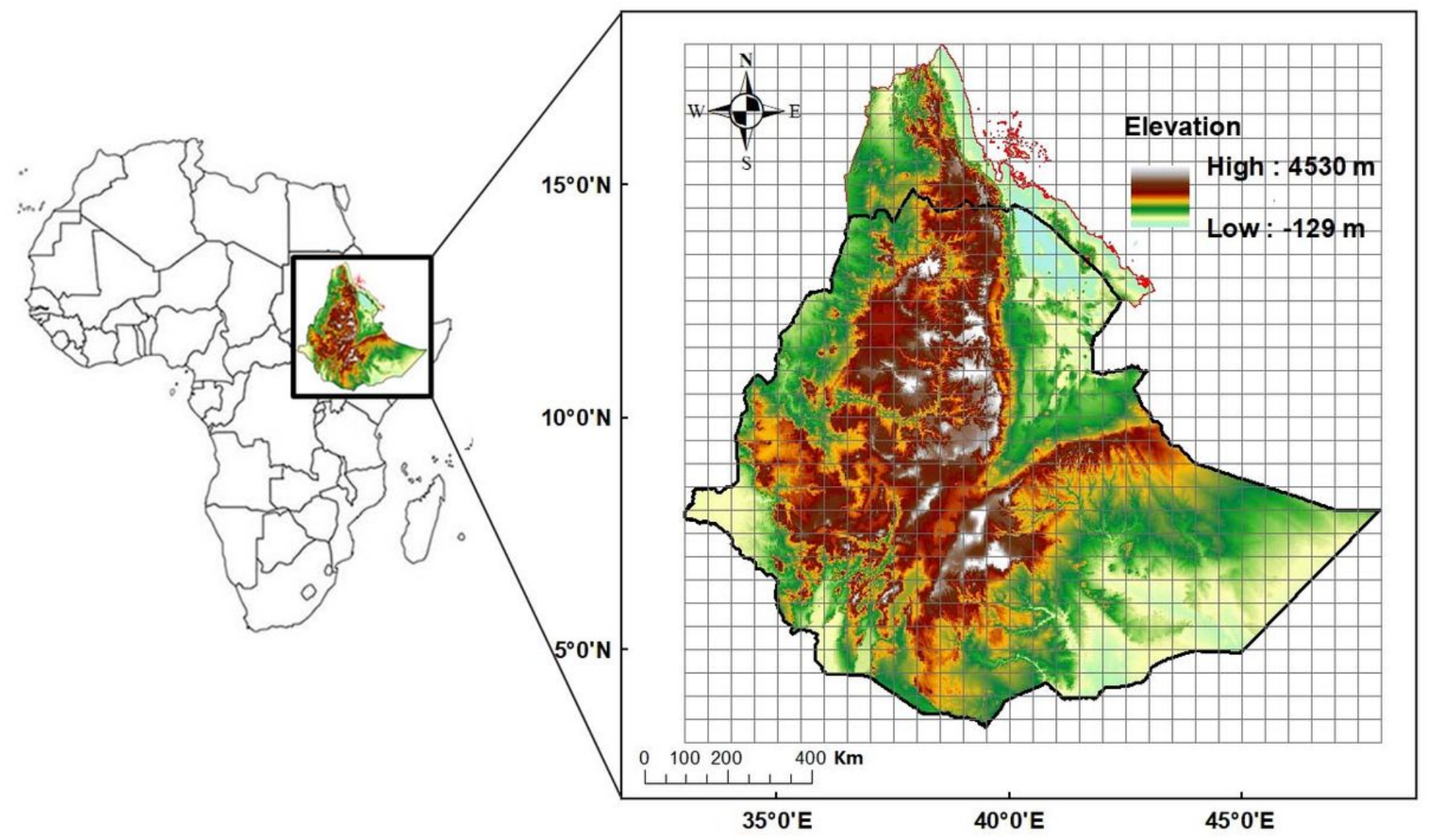

Figure 1

Location and topographic map of Ethiopia and Eritrea in the horn of Africa. 

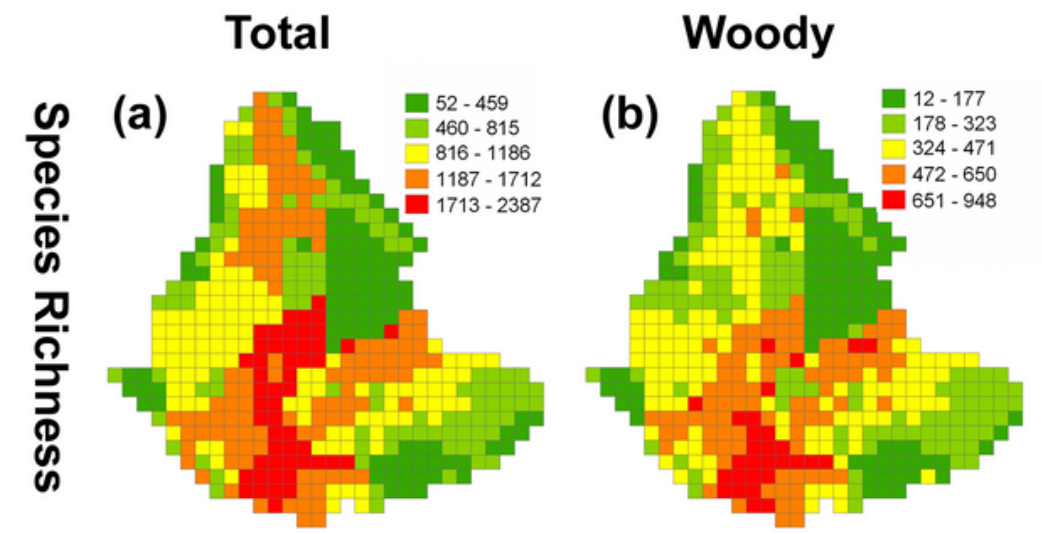

\section{Herbaceous}
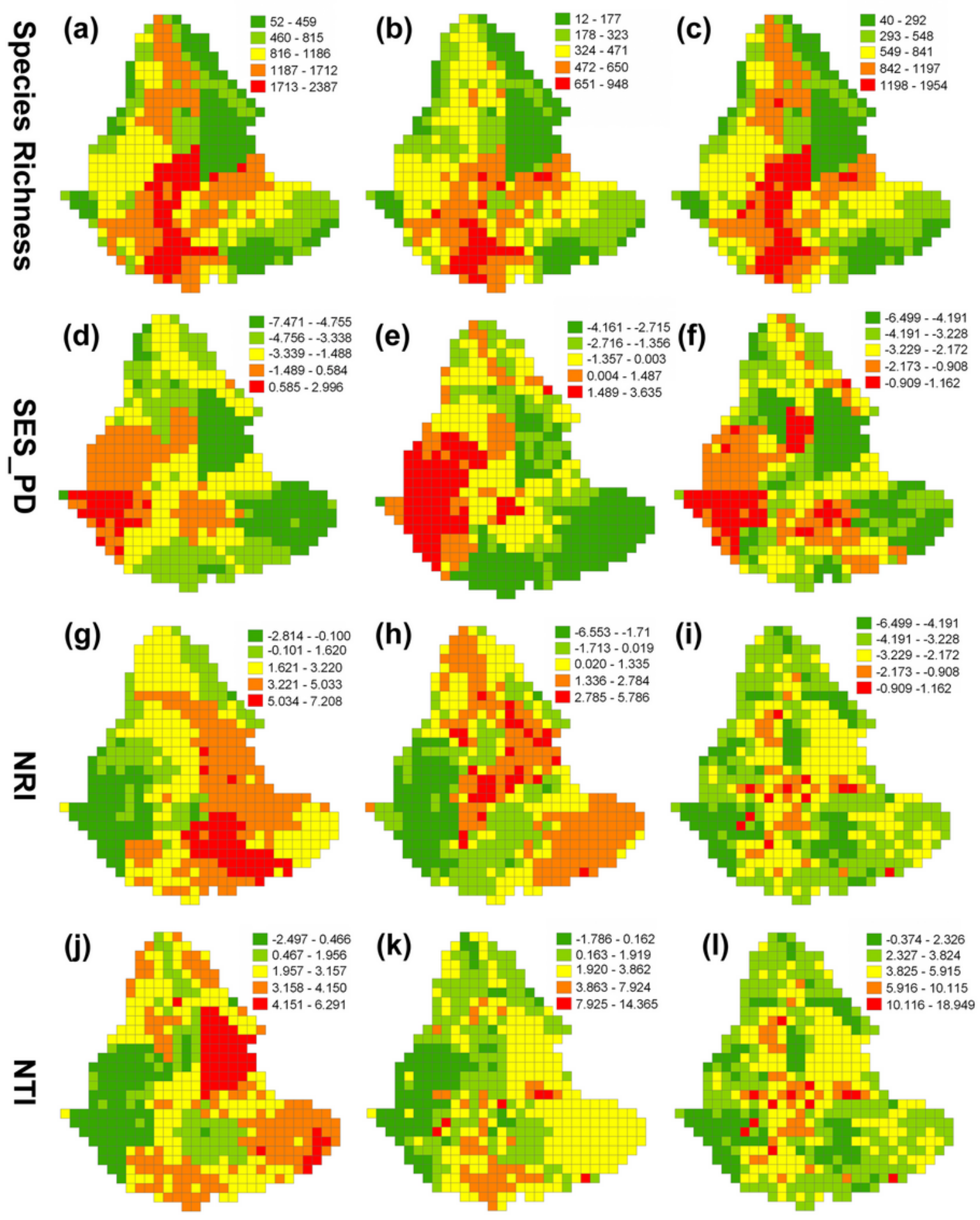

\section{Figure 2}

Spatial patterns for diversity and phylogenetic structures of total, woody and herbaceous seed plants across the geographical regions of Ethiopia and Eritrea. (a-c) taxonomic diversity (species richness); (df) phylogenetic diversity (SES_PD); ( $g-i)$ phylogenetic structure (NRI) and $(j-I)$ phylogenetic structure (NTI). 

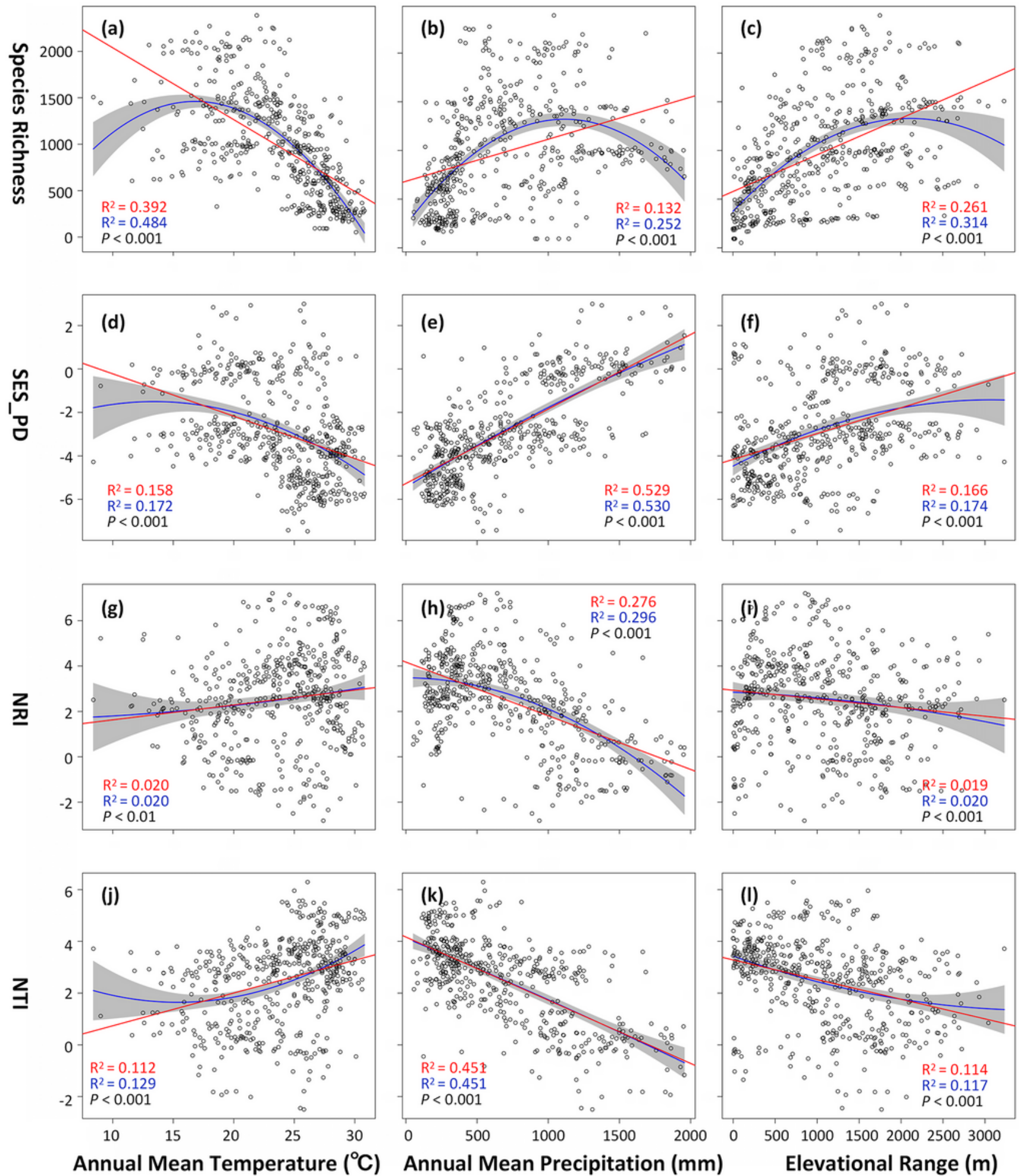

\section{Figure 3}

Relationships between environmtal factors and indices of total plants diversity and phylogenetic structures. $(a, d, g, j)$ species richness, SES_PD, NRI, NTI and annual mean temperature; $(b, e, h, k)$ species richness, SES_PD, NRI, NTI and annual mean precipitation; (c,f,i,l) species richness, SES_PD, NRI, NTI and elevational range..The red line shows linear regression analysis, the blue line represents nonlinear regression analysis and the gray represents $95 \%$ confidence interval. 

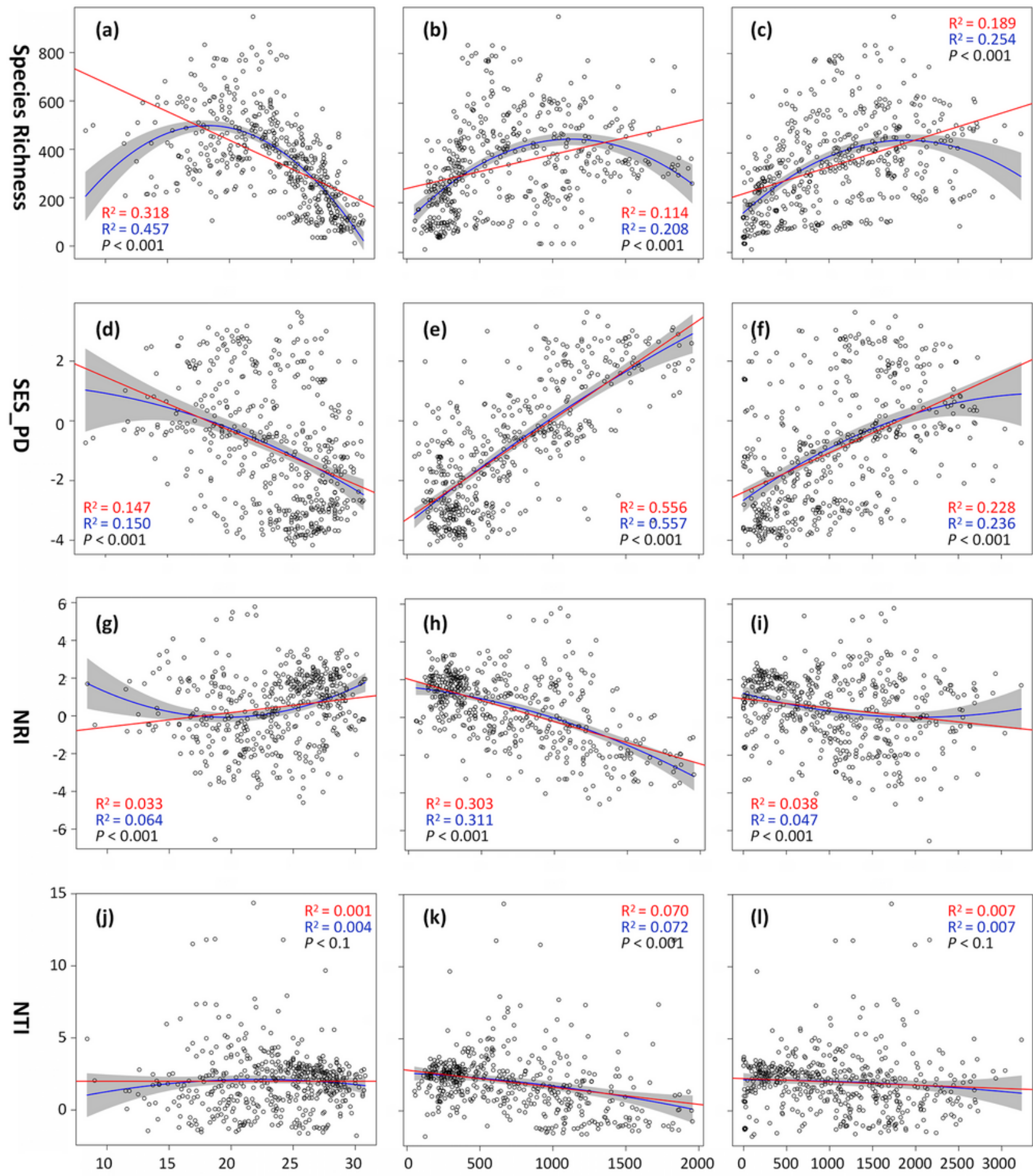

Annual Mean Temperature $\left({ }^{\circ} \mathrm{C}\right) \quad$ Annual Mean Precipitation $(\mathrm{mm})$

Elevational Range (m)

\section{Figure 4}

Relationships between environmtal factors and indices of herbaceous plants diversity and phylogenetic structures. $(a, d, g, j)$ species richness, SES_PD, NRI, NTI and annual mean temperature; $(b, e, h, k)$ species richness, SES_PD, NRI, NTI and annual mean precipitation; (c,f,i,l) species richness, SES_PD, NRI, NTI and elevational range..The red line shows linear regression analysis, the blue line represents nonlinear regression analysis and the gray represents $95 \%$ confidence interval. 

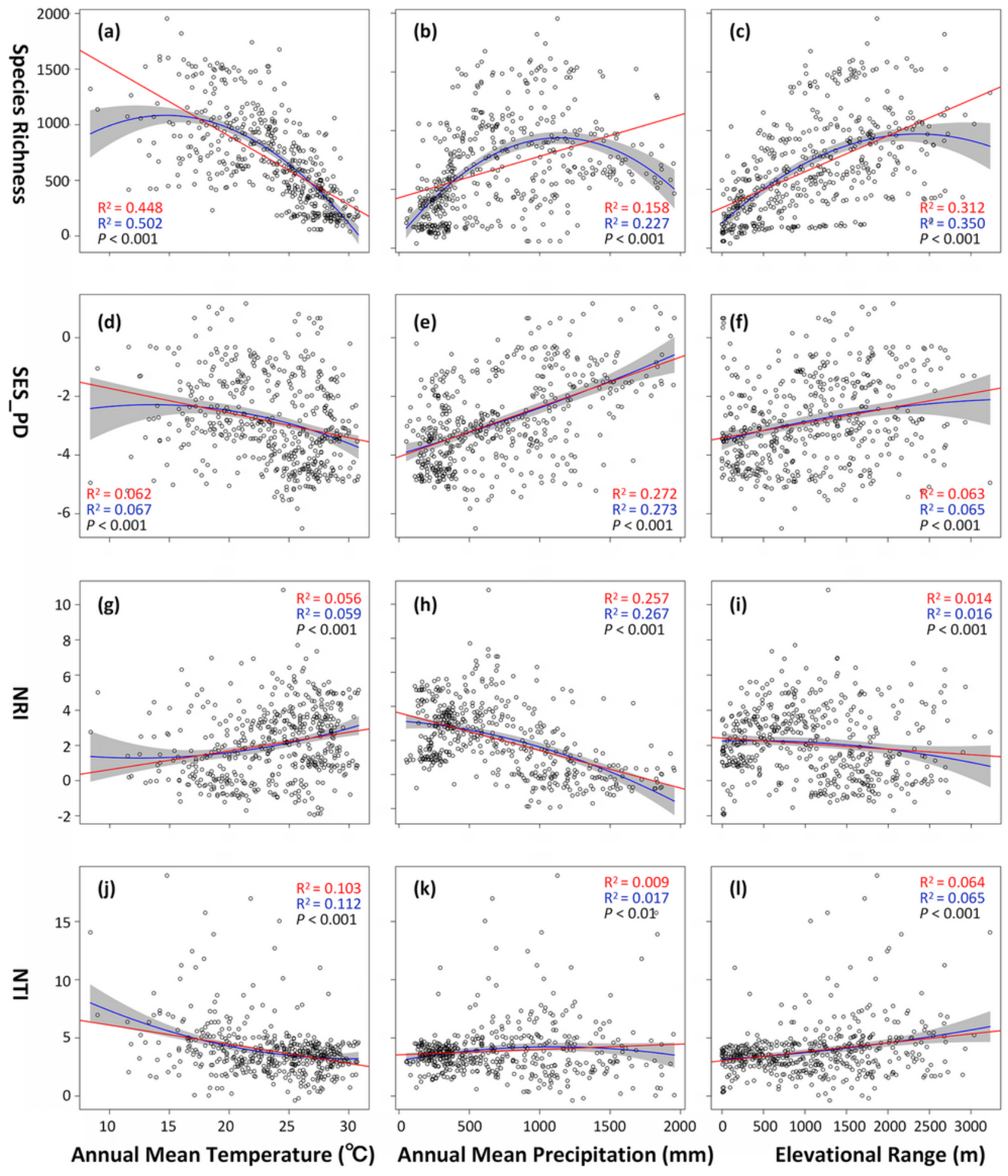

\section{Figure 5}

Relationships between environmtal factors and indices of woody plants diversity and phylogenetic structures. $(a, d, g, j)$ species richness, SES_PD, NRI, NTI and annual mean temperature; $(b, e, h, k)$ species richness, SES_PD, NRI, NTI and annual mean precipitation; (c,f,i,l) species richness, SES_PD, NRI, NTI and elevational range..The red line shows linear regression analysis, the blue line represents nonlinear regression analysis and the gray represents $95 \%$ confidence interval. 